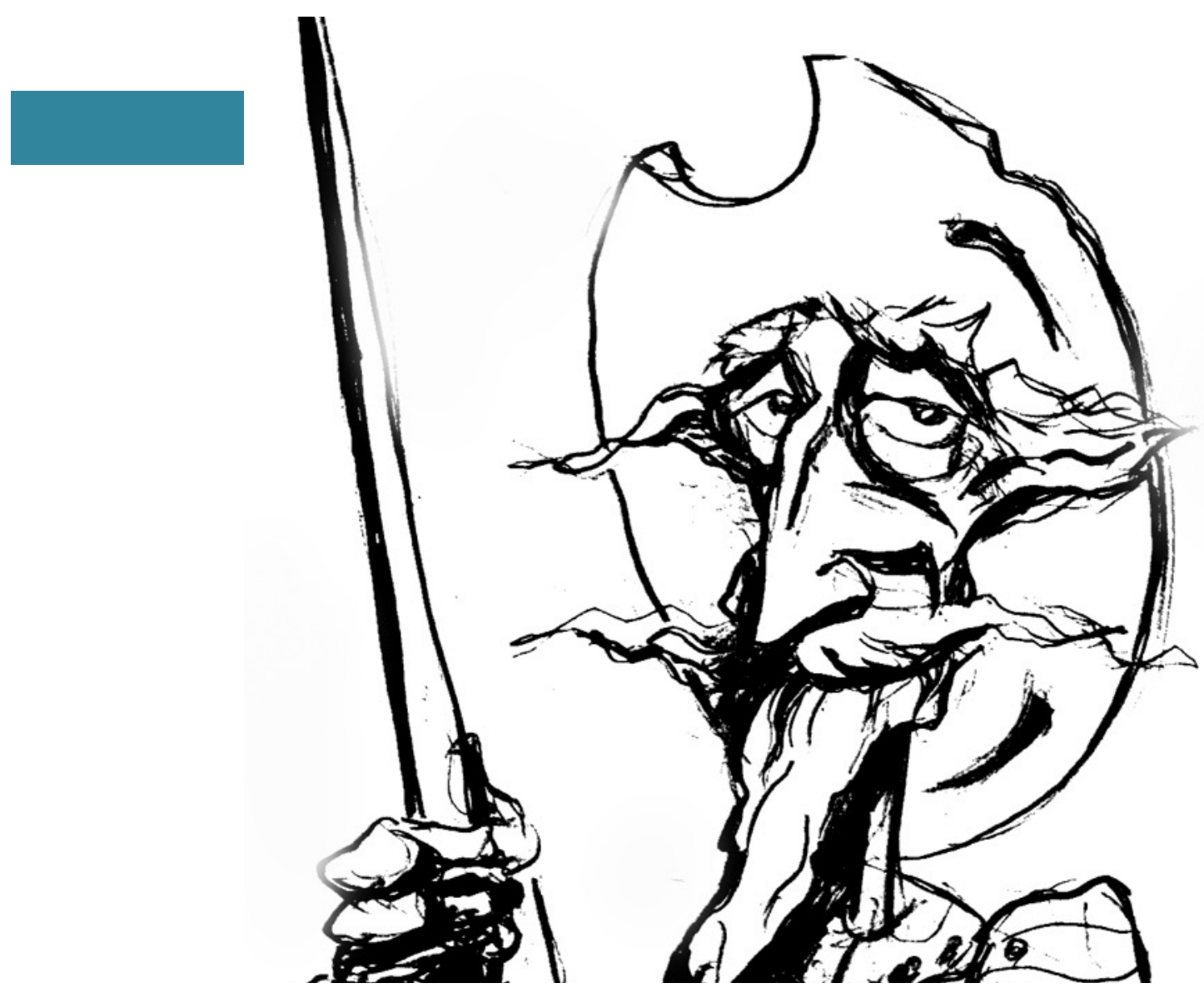

Las Huelgas Ferroviarias (1950-1951).

Una interna peronista.

[Joaquín Aldao] 


\section{Las Huelgas Ferroviarias (1950-1951). Una interna peronista*}

\section{The Railway Strikes (1950-1951). A Peronist internal conflict.}

JOAQUÍN A. ALDAO

\section{Resumen}

En el presente artículo se analizan las huelgas ferroviarias (1950-1951), presentadas como un conflicto político en un contexto de hegemonía peronista en el gremio y contextualizadas en un proceso de profundas transformaciones en las prácticas sindicales. Estas transformaciones, se abordan en el marco de las tensiones políticas que produjo el fortalecimiento institucional del sindicalismo en el movimiento peronista, y en el imprevisto cambio en la relación entre el sindicato y el Estado que precede al proceso de nacionalización de los ferrocarriles. Estas huelgas, son la expresión de máxima tensión en el vínculo entre la identidad ferroviaria y el peronismo.

\section{Palabras clave}

Primer peronismo - huelgas - ferroviarios sindicalismo - nacionalización de los ferrocarriles

\begin{abstract}
This article analyzes the railroad strikes (19501951), presented as a political conflict in a context of Peronist hegemony in the union, and contextualized in a process of deep transformations in union practices. These transformations are addressed within the framework of the political tensions produced by the institutional strengthening of trade unionism within the Peronist movement, and in the unforeseen change in the relationship between the union and the State which precedes the process of nationalization of the railways. These strikes are the expression of maximum tension in the link between railway identity and Peronism.
\end{abstract}

\section{Key Words}

First Peronism - strikes - railways - syndicalism - nationalization of railways

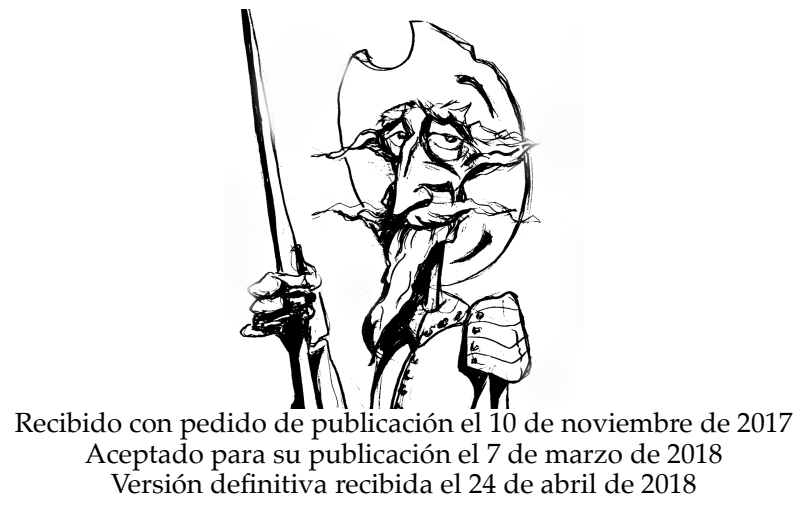

Joaquín A. Aldao, Universidad Nacional de Mar del Plata, Consejo Nacional de Investigaciones Científicas y Técnicas, Argentina; e-mail: joacoaldao@hotmail.com

* Agradezco las críticas y sugerencias de los evaluadores anónimos de Revista Prohistoria

Esta obra se publica bajo licencia Creative Commons. Atribución-NoComercial-CompartirIgual Internacional

Aldao, Joaquín A. "Las Huelgas Ferroviarias (1950-1951). Una interna peronista”, Prohistoria, Año XXI, núm. 29, jun. 2018, pp. 93-114.

\section{Introducción}

En la última década se produjeron algunas aproximaciones historiográficas a las huelgas ferroviarias de 1950-1951,, aportes valiosos para comprender un

${ }^{1}$ MENGASCINI, Hugo “Conflictos y huelgas ferroviarias durante el periodo peronista. El caso de los trabajadores peronistas de Tandil", $3^{\circ}$ Jornadas sobre la política en Buenos Aires en el Siglo XX, La Plata, 2008, [en línea] http://ww.historiapolitica.com/datos/biblioteca / 
episodio que no había sido tratado, más que superficialmente, por los estudios clásicos sobre movimiento obrero y primer peronismo. ${ }^{2}$ Estos abordajes recientes, nos permite recuperar algunas pistas importantes sobre la conflictividad ferroviaria en el período, con detallada documentación del conflicto a nivel nacional ${ }^{3} \mathrm{o}$ en algunas plazas importantes como Bahía Blanca ${ }^{4}$ o Rosario. ${ }^{5}$ Todos ellos, concluyen en una nueva corriente de la historiografía sobre movimiento obrero y primer peronismo, que pone en cuestión el lugar políticamente heterónomo del sindicalismo durante el primer peronismo, preponderando las proyecciones políticas del mismo. ${ }^{6}$

El presente artículo pone a la huelga en conexión con las transformaciones que sufren las prácticas sindicales en el proceso de institucionalización de las relaciones político sindicales y de creciente politización del campo sindical, en un contexto de hegemonía peronista. Para ello se recurre a fuentes específicas del sindicato ferroviario (el Obrero Ferroviario y Actas de la Comisión Directiva) complementadas con las fuentes periodísticas de tirada nacional que cubrieron la huelga de forma pormenorizada (La Prensa y La Nación). Se destaca en el análisis, para comprender el desarrollo del conflicto, las transformaciones que la nacionalización de los ferrocarriles trajo tanto en la relación del sindicato de la Unión Ferroviaria con un sector del gobierno y en las prácticas sindicales, no solo por el compromiso político de una dirigencia fuertemente identificada con el peronismo, sino por el nuevo rol que desempeñan como miembros del directorio de la empresa Ferrocarriles Argentinos.

Haciendo una breve recapitulación de los años previos a las huelgas, desde los primeros meses del año 1947, la nacionalización de los ferrocarriles va a plantear una nueva relación del sindicato del riel con el Estado -y el gobierno peronista- ahora a cargo de la administración ferroviaria. A grandes rasgos, los intentos de un sector del gobierno por absorber funciones del sindicalismo ferroviario, con el objetivo de consolidar una dirección unívoca, eficiente, de la actividad ferroviaria, es la característica central que signa esta etapa de reconfiguración del peronismo ferroviario. Pero este fenómeno se inscribe en un contexto político que lo excede.

\footnotetext{
3jornadas/mengascini.pdf; CONTRERAS, Gustavo “Ferroviarios. Un capítulo de sus luchas: Las huelgas ferroviarias de fines de 1950 y principios de 1951", Ponencia presentada en el $V$ Congreso de Historia Ferroviaria. Palma de Mallorca, España, 2009; MARCILESE, José "El sindicalismo ferroviario durante el primer peronismo. El caso de la Unión Ferroviaria de Bahía Blanca", IX Jornadas Nacionales - VI Latinoamericanas Hacer la Historia, Bahía Blanca, Universidad Nacional del Sur, 2010; BADALONI, Laura “Control, memoria y olvido. 'Marcha de la Paz' y huelga ferroviaria durante el primer gobierno peronista", historiapolitica.com, Mar del Plata, 2013.

2 Para una caracterización de lo que definimos como estudios clásicos del movimiento obrero y primer pero ismo ver ALDAO, Joaquín Alberto "Construcción y crítica al paradigma clásico de los estudios sobre movimiento obrero y primer peronismo. La emergencia del campo sindical argentino, propuesta de una alternativa interpretativa", Sudamérica: Revista de Ciencias Sociales, 2015, núm. 4, pp. 177-196.

${ }^{3}$ CONTRERAS, Gustavo "Ferroviarios...", cit.

${ }^{4}$ MARCILESE, José "El sindicalismo ferroviario...", cit.

${ }^{5}$ BADALONI, Laura "Control, memoria y olvido...", cit.

${ }^{6}$ CONTRERAS, Gustavo “¿Apéndice estatal? La CGT durante el primer gobierno peronista: funcionamiento institucional y proyecciones políticas", en ACHA, Omar y QUIROGA, Nicolás (coordinadores) Asociaciones y política en la Argentina del siglo veinte. Entre prácticas y expectativas; Editorial Prometeo, Buenos Aires, 2015, pp. 109- 128.
} 
Durante los años previos a la huelga (1947-1951), el nacimiento y consolidación del Partido Peronista producen una intensificación de la competencia interna que se traslada al parlamento, ${ }^{7}$ sumado a una cada vez más férrea voluntad de orden y disciplina que emana desde los centros de poder partidario y gubernamentales, que buscan estabilizar la situación "desde arriba". Una consecuencia de este contexto de tensión entre creciente conflictividad e insistente búsqueda de orden, es que la participación obrera en la toma de decisiones políticas comienza a perder espacio en el Partido Peronista. ${ }^{8}$

Sin embargo, la consolidación de la dirigencia política peronista en el partido, se topa con el poderío de la C.G.T., a esta altura inobjetable. Los ferroviarios de la U.F. cuentan con un nutrido plantel de funcionarios en la Secretará de Trabajo y Previsión (S.T.P.), en el parlamento e, inclusive, en cargos ejecutivos, ${ }^{9}$ que les van a permitir cobrar protagonismo en la defensa del sindicato y la central. Dos dimensiones del enfrentamiento entre un sector de dirigentes políticos del Partido Peronista y los ferroviarios son necesarias mencionar como antecedentes del conflicto para encuadrarlo en una interna politica.

La primera es parlamentaria y, a su vez, tiene dos momentos significativos. El primer momento es la disputa por la aprobación del proyecto de ley del seguro social (1947-1948), presentado por el presidente del P.P., Alberto Tessaire. El proyecto buscaba centralizar el sistema previsional sindical dentro del Ministerio de Salud, lo que implicaba despojar a los sindicatos de la administración de las cajas jubilatorias, un elemento central para comprender el proceso de consolidación institucional del sindicato y la C.G.T. Una vez fracasado el proyecto parlamentario del seguro social- elemento que incidió fuertemente en la salida de A. Hernández como Sec. Gral. de la C.G.T. y en el paso a retiro de parte de Comisión Directiva (C.D.) de la U.F.- ${ }^{10}$ se pone en marcha el segundo momento. Este consiste, una vez creado el Ministerio de Transportes de la Nación, en un plan ministerial que busca absorber el sistema previsional ferroviario en el Ministerio de Transportes, a través de un proyecto de la dirección de asistencia social y sanitaria, conducida por Manuel Fresco.

La segunda dimensión es político-sindical, temporalmente se desarrolla en paralelo a la primera, y es la prolongación de la interna por carriles sindicales. También tiene dos momentos. El primero, que comienza por 1948, consiste en el intento de afiliación de todos los empleados y obreros estatales, entre ellos los ferroviarios, en la Confederación del Personal Civil de la Nación (C.P.C.N.), poniendo en marcha una campaña que combina la presión de invocar al presidente de la nación como principal promotor de la afiliación, con la propuesta de la doble afiliación sindical (a la U.F. y a la nueva central estatal,

\footnotetext{
${ }^{7}$ MACKINNON, Moria Los años formativos del Partido Peronista, Siglo XXI/ Instituto Di Tella, Buenos Aires, 2002, p. 85.

8 AELO, Oscar Humberto "El Partido Peronista argentino: diseños organizativos y prácticas políticas (1947-1955)", en Topoi, Universidad Federal de Rio de Janeiro, Rio de Janeiro, núm.17 (33), 2016, pp. 602-625.

${ }^{9}$ ALDAO, Joaquín Alberto “El ejército civil de los trabajadores. Los ferroviarios y el peronismo, esbozo de una alternativa interpretativa", en Anuario INIHEP, Ministerio de Cultura de la Nación, Buenos Aires, 2016, pp. 51-68.

${ }^{10}$ Para un desarrollo de este período desde el sindicato de la U.F. ver ALDAO, Joaquín Alberto "Los ferroviarios y la defensa del sistema de cajas jubilatorias durante el primer peronismo. La interna político-parlamentaria y los alcances sindicales del conflicto", Actas de las XVI Jornadas Interescuelas / Departamentos de Historia, Mar del Plata, 9, 10 y 11 de agosto de 2017.
} 
dirigida por funcionarios del gobierno). A inicios de 1950, con una nueva dirigencia en la U.F. y la consolidación de la hegemonía peronista en el sindicato, el proyecto de doble afiliación es explícitamente abandonado por los directivos de la C.P.C.N, a instancias del propio presidente. ${ }^{11}$ Sin embargo, promediando el año 1950, los propios dirigentes ferroviarios denuncian la creación de "ateneos peronistas ferroviarios", que actúan en paralelo a las seccionales $\mathrm{y}$, al igual que la confederación antes mencionada, socaban la legitimidad representativa del sindicato sobre sus afiliados. ${ }^{12}$ Las huelgas ferroviarias que inician a fines de 1950, entonces, hunden sus raíces en este contexto paradójico de consolidación hegemónica y extrema conflictividad interna del peronismo.

Un último elemento, teórico, es necesario destacar para introducirnos al desarrollo de las huelgas. Desde el punto de vista de la identificación de los ferroviarios con el peronismo -articulación que se afianza de forma prematura, hacia $1944-{ }^{13}$ la consolidación de la hegemonía peronista en el sindicato trae aparejado un efecto concreto: el aumento de la tensión entre la particularidad de la identidad ferroviaria y el peronismo, en cuanto universal. Esta tensión, llega al límite hacia 1950 y es un elemento central para comprender la precipitación del conflicto. ${ }^{14}$ Luego de los primeros años, cuando prevalece la satisfacción de las demandas ferroviarias, crece la exigencia -en nombre de un universal peronistade superar los intereses corporativos y realizar sacrificios por el interés nacional. La tensión puede resumirse en una pregunta que adquiere una extraordinaria carga semántica: ¿Peronistas ferroviarios o Ferroviarios peronistas? La pregunta ilustra el corrimiento de la frontera antagónica, redefiniendo los límites del peronismo ferroviario.

\section{Los meses previos a la primera huelga}

Hacia 1950, la C.D. de la U.F. logra mantener su posición en el campo sindical luego de las batallas por mantener los afiliados, el control del sistema previsional y, con ello, aportar sustancialmente a la consolidación del lugar de la C.G.T. en el movimiento peronista. En las bases, lejos de un clima de agradecimiento, crece la sospecha de una dirección más preocupada por la política sindical y parlamentaria que por los asuntos gremiales. Al descontento que produce la larga espera por mejoras salariales (la inflación continúa en ascenso), se suman los descuentos por planilla del aporte previsional, las cuotas

\footnotetext{
11 En marzo de 1950, el concejo directivo superior de la C.P.C.N. resuelve que todos los ferroviarios dejan de pertenecer a la organización y se disuelven las seccionales compuestas por trabajadores ferroviarios (Firman Alfredo Villafañe y Dante Viel, presidente y secretario. E.O.F., 589:11). Poco tiempo antes, Pablo C. López informaba al sindicato sobre la reunión con el presidente Perón y los directivos de la C.P.C.N., en dónde este le aseguraba a aquél que, el objetivo de la confederación, era sindicalizar a los trabajadores del Estado no sindicalizados, no disputar representación la sindical a la U.F. (El Obrero Ferroviario, 586-587:6).

${ }^{12}$ Esta última práctica va en consonancia con la absorción de las unidades básicas sindicales en el P.P., borrando las huellas de extracción sindical de las mismas. AELO, Oscar y QUIROGA, Nicolás "Modelos en conflicto. El partido peronista en la provincia de Buenos Aires, 1947-1955", en Estudios Sociales, núm. 30, 2006.

${ }^{13}$ ALDAO, Joaquín "El ejército civil de los trabajadores...", cit.

${ }^{14}$ Respecto a la caracterización teórica de esta tensión entre particularidad y universalidad en la articulación de una cadena equivalencial y su efecto en la dinámica de los límites de una identidad popular ver LACLAU, Ernesto Misticismo, retórica y política, Fondo de Cultura Económica, México D. F., 2002, p.124.
} 
sindicales y, de forma inédita, las donaciones a la Fundación Eva Perón. ${ }^{15}$ La reforma del estatuto de la C.G.T. en 1950 y el recrudecimiento de la voluntad disciplinadora del gobierno, obliga a reformular el escenario discursivo en el mundo ferroviario.

En este contexto, la convulsión en las seccionales choca con la rigidez de la dirigencia, preocupada por sostener la disciplina sindical a través del instrumento estatutario de la intervención. A mediados de mayo de 1950, se interviene la seccional de Tolosa. Presidida por Lorenzo Martorelli, la seccional rechaza la reforma del estatuto de la C.G.T. que implica la adopción de la doctrina peronista por parte del gremio y la central. Su posición es en defensa de la libertad sindical, aduciendo que se viola el art. $4^{\circ}$ del estatuto referente a la prescindencia. ${ }^{16} \mathrm{Al}$ mes siguiente, en la asamblea general de la U.F., Martorelli intenta ingresar a la misma en calidad de representante de Tolosa, desconociendo la intervención. Naturalmente, su credencial es rechazada, pero es importante el fundamento del rechazo. La comisión arbitral de la asamblea no lo acusa de "enemigo del justicialismo" para negarle su credencial -como se había hecho con el socio Carlos Polverini el año anterior- ${ }^{17}$ sino que alegan que su accionar busca "sembrar la confusión en el terreno del justicialismo". Martorelli, no tenía un mínimo antecedente que permita dudar de su apoyo al peronismo. La sanción se presenta como ejemplar, advirtiendo que contra el mantenimiento de la unidad y disciplina "conspiran todas las actuaciones similares o parecidas al alzamiento de la seccional Tolosa".

Lo que está en juego es la definición de peronismo. Los dirigentes que se encargan de custodiar el "verdadero" peronismo, obligan a la redefinición de la frontera que divide los dos campos antagónicos. Ya no basta con proclamarse peronista para serlo, ni con apoyar al gobierno, también se debe estar conforme con la dirigencia de la U.F. Desde 1949, esta situación va in crescendo y se vuelve asfixiante para las dirigencias seccionales disconformes. Arrinconando las disidencias con las intervenciones, se barre con el complejo panorama de expectativas, intereses y necesidades de las bases, proponiendo un nuevo antagonismo.

En este contexto, un elemento en común, la identidad ferroviaria ${ }^{18}$ va a funcionar como amalgama, como elemento articulador, para que peronistas, radicales, socialistas, comunistas; en fin, obreros y empleados ferroviarios, se

${ }^{15}$ En los años de gestión de la C.D. presidida por Pablo C. López (1948-1950) el gremio ferroviario sufre el aumento de la cuota social, de los aportes previsionales y el establecimiento de cuotas mensuales para el periódico del sindicato y las colonias de vacaciones. Además, a la tradicional donación anual de medio jornal para las arcas del gremio, se adicionan donaciones a la Fundación Eva Perón de medio jornal anual y de un jornal completo circunstancial, ya sea del aguinaldo, de cada aumento de sueldo o del cobro de retroactivo de aumentos. De la misma forma, la C.G.T. establece la donación a la Fundación de los jornales de los días 1 de mayo y 12 de octubre de todos los trabajadores afiliados, entre los que se encuentran los ferroviarios. Al implementarse el descuento por planilla de las donaciones mencionadas anteriormente, estas se tornaban prácticamente obligatorias. Para diciembre de 1949 la Unión Ferroviaria llevaba donados \$12.000.000 a la Fundación Eva Perón (El Obrero Ferroviario, 572:4; 579-580:4; 585:2; 591-592:23 y CT; 594:2).

${ }^{16}$ Este punto acercaba a los ferroviarios con la posición de la C.D. del gremio de maquinistas. Respecto a las posiciones en la ajustada votación que aprueba el estatuto en la C.G.T. (a la que se oponen incluso miembros de la U.F.) ver DOYON, Louise Perón y los trabajadores: Los orígenes del sindicalismo peronista, 1943-1955, Siglo XXI, Buenos Aires, 2006, p. 319.

${ }^{17}$ El Obrero Ferroviario, 579-580:4.

${ }^{18}$ ALDAO, Joaquín Alberto "Construcción y crítica...", cit.; ALDAO, Joaquín Alberto "El ejército civil de los trabajadores...", cit. 
presenten como representantes legítimos del gremio del riel. Un significante va a ser clave en esta nueva articulación, la libertad sindical. Este elemento une a dirigentes de varios colores políticos y, también, a una parte importante de las bases, que busca canalizar las expectativas de mejoras desatadas por la nacionalización ferroviaria. Desde fines de 1949, cuando el convulsionado panorama político recrudece, cobran visibilidad en el gremio del riel las primeras formas organizativas que van a dar cohesión y coordinación a la huelga, las comisiones de enlace. Estas comisiones, compuestas por dirigentes de distintas seccionales y líneas ferroviarias, son los primeros esbozos de una articulación sindical que elude al verticalismo del sindicato ferroviario.

\section{La primera huelga}

Un año después de esas primeras reuniones, con la situación salarial en continuo deterioro y un lento procesamiento de las demandas por parte de la dirigencia, el 15 de noviembre de 1950, peones y guardabarreras del F.C.N.G.R. ${ }^{19}$ inician un paro de actividades. Si bien el alcance de este paro es limitado, afecta el tramo entre la capital federal y la capital bonaerense, genera serios trastornos en la vida cotidiana de los ciudadanos de las dos urbes. La adhesión de los guardabarreras le da mayor visibilidad al conflicto ya que estos mantienen las barreras de los paso a nivel bajas, entorpeciendo seriamente el tráfico automotor en el conurbano bonaerense y La Plata. ${ }^{20}$ Además, el conflicto tiene una función catalizadora, se propaga por las seccionales de las distintas líneas la discusión en torno al apoyo o no a la medida, a la justicia o no de la demanda.

Cinco días después, con la noticia de la cesantía de los artífices de la huelga, el conflicto se agrava y logra paralizar el ingreso de los trenes a la estación de Constitución por varias horas. Durante ese día, se realizan algunas asambleas informales en la misma estación, y se producen los primeros contactos de dirigentes con funcionarios del Ministerio de Transporte. ${ }^{21}$ Al día siguiente, la dirigencia de la U.F. se rehúsa a recibir a los huelguistas, por lo que estos se reúnen en el local de la seccional Buenos Aires del F.C.N.G.R. Se registra la participación de delegados de Tolosa, Remedios de Escalada y "Km. $\mathrm{V}^{\prime \prime}$ (Gerli), todos puntos claves para comprender el impacto territorial del conflicto. Allí, se aclama a Manuel Santos como presidente de la asamblea. ${ }^{22} \mathrm{Al}$ día siguiente, el paro de la actividad ferroviaria en el F.C.N.R. y el F.C.N.G.S. es casi total.

Las discusiones se extienden a los galpones de Rosario (F.C.N.G.M.), ${ }^{23}$ Tandil y Bahía Blanca. ${ }^{24}$ Finalmente, en la ciudad santafecina, la medida tiene un alcance muy limitado, pero prenderá en las ciudades bonaerenses. El 22 de

\footnotetext{
${ }^{19}$ Ferrocarril Nacional General Roca. A partir de aquí, el Ferrocarril Nacional General Sarmiento (F.C.N.G.S.), el General Mitre (F.C.N.G.M.), el General San Martín (F.C.N.G.S.M.) y el General Belgrano (F.C.N.G.B.).

${ }^{20}$ La Nación, 20 de noviembre de 1950, p. 4.

${ }^{21}$ Se entrevistan con el Jefe de Tráfico del F.C.N.G.R., J. Murgizur. La Nación, 21 de Noviembre, p. 4.

${ }_{22}$ También se registra la participación de un delegado del F.C.N.G.S. La Nación, 22 de noviembre de 1950, p. 4.

${ }^{23}$ BADALONI, Laura "Control, memoria y olvido...", cit., p. 11.

24 MARCILESE, José "Los trabajadores ferroviarios de Bahía Blanca durante el primer peronismo (1945-1955)", en Mundos do Trabalho, Associação Nacional de História, Santa Catarina, núm. 5 (9), p. 275.
} 
noviembre se paralizan los servicios en Bahía Blanca y, el 23, una asamblea aclama el apoyo a los Peones en Tandil. ${ }^{25}$ Con el paso de los días, el reclamo salarial deriva en un reclamo por la renuncia de la C.D. de la U.F., que decide condenar la huelga.

Mientras tanto, en la sede central del sindicato, el 23 a la tarde, se reúne a la Junta Consultiva de la U.F. Esta junta es un cuerpo integrado por los presidentes de 43 seccionales (las cabeceras de los ferrocarriles que confluyen en Buenos Aires y las más importantes del interior). En Haedo, Remedios de Escalada y Gerli, se suspenden las asambleas de huelguistas para que las autoridades seccionales asistan a la reunión. ${ }^{26} \mathrm{El}$ nuevo cuerpo recibe un informe de la Comisión Directiva (C.D.) sobre los hechos ocurridos y la renuncia en pleno de la misma. Sin embargo, y como era esperable de un cuerpo convocado por la dirigencia, es unánime el rechazo tanto a la huelga como a la renuncia de la C.D. ${ }^{27}$ La declaración resultante propone: "Exhortar a los ferroviarios que se han plegado a los paros a volver inmediatamente al trabajo, respetando la disciplina sindical, base de las conquistas del gremio, y autoriza a la comisión directiva para que pida la aplicación de la ley que reprime el sabotaje..." 28

Al día siguiente, los dirigentes de la U.F. vuelven a reunirse con Evita y con el Ministro de Transportes, J. F. Castro. El enfrentamiento con el diario La Prensa toma protagonismo, dado que este medio publica que, la "santa del trabajo", es árbitro en el conflicto. Sin embargo, al otro día, el gremio desmiente esta versión aduciendo que "sólo presta su consejo y ayuda". En este sentido, para la dirigencia es necesario afirmar la legitimidad institucional de las autoridades sindicales.

Como respuesta, ese mismo día se realiza una asamblea paralela con la presencia de varios presidentes seccionales que quedan desplazados de la Junta Consultiva, y se consolida la denominada Comisión Consultiva de Emergencia (C.C.E.). Esta reúne a los dirigentes que vienen trabajando en las comisiones de enlace desde hace un año, y suma nuevas adhesiones. La nueva comisión va a disputar la legítima conducción del gremio. El 24 a la tarde, en una multitudinaria asamblea en Gerli, se rubrica la legitimidad del nuevo cuerpo. La huelga se levanta ese día, luego de una reunión con el Ministro de Transportes en la que los huelguistas entregan un petitorio con las demandas salariales y exigen la renuncia de la C.D. Este último punto, decía la resolución de la asamblea, "proseguirá dilucidándose dentro del terreno gremial". ${ }^{29}$

\section{El movimiento huelguístico se consolida. Una huelga bonaerense}

En términos generales, el movimiento huelguístico que nace en noviembre de 1950 y se extiende hasta enero de 1951, tiene su epicentro en la provincia de Buenos Aires. Dos diferencias se evidencian de forma inmediata respecto a las huelgas generales de 1917 y 1947. Una, que no cuenta con el reconocimiento del sindicato (la Federación Obrera Ferrocarrilera en el primer caso y la U.F. en el

\footnotetext{
${ }^{25}$ MENGASCINI, Hugo “Conflictos y Huelgas...”, cit., pp. 11-13.

${ }^{26}$ La Nación, 23 de noviembre, p. 5.

${ }^{27}$ Por la J.C. toma protagonismo Clemente Boscaroli, presidente de una de las seccionales de Rosario, quién tomará la palabra representando a la junta ante Perón en la reunión del 27 de noviembre (El Obrero Ferroviario, 577-578:2).

${ }^{28}$ El Obrero Ferroviario, 497:4.

${ }^{29}$ La Nación, 24 de noviembre de 1950, p. 4.
} 
segundo) y dos, con estrecha relación causal con la primera, que nunca se paraliza todo el sistema ferroviario (sus cinco líneas). No buscamos restar importancia al movimiento al destacar estas características, por el contrario, si ponderamos el impacto sobre la economía y la vida cotidiana de los millones de personas afectadas, fue uno de los conflictos sindicales más importantes del período de los primeros gobiernos peronistas. Sin embargo, resaltar esta parcialidad es precondición para inscribir el conflicto en una interna, que no solo engloba a toda la institución sindical ferroviaria, sino que tiene aristas que la exceden. Esta interna cobra fuerza particular en la provincia de Buenos Aires y la Capital Federal. ${ }^{30}$ Desde una perspectiva topográfica, y considerando el centralismo de la institución ferroviaria, la huelga es también un "asedio al castillo" ferroviario, a su sede central. Lejos de ser una simple metáfora, el 21 de diciembre, un día después de que la C.G.T intervenga el sindicato, cientos (o miles) $)^{31}$ de ferroviarios se enfrentan a la policía en la puerta de Independencia 2880, con el objetivo de expulsar a los interventores y tomar las riendas del gremio.

MAPA 1. Seccionales que participan activamente en alguna o todas las huelgas ferroviarias entre noviembre de 1950 y enero de 1951

${ }^{30}$ La ciudad de Rosario vive momentos convulsionados también, pero de alcance limitado. Según el único trabajo sobre la huelga en Rosario, un galpón y los guardas de una línea se pliegan a la primera huelga, a lo que se suman algunos arrestos de guardas en reuniones posteriores. BADALONI, Laura "Control, memoria y olvido...", cit., pp. 11-13.

${ }^{31}$ Según el diario La Prensa son miles los que intentan llegar a la sede de la UF, según el órgano oficial del gremio son unas 300 personas (La prensa, 22 de diciembre de 1950, p. 6 y EOF, 598599). 


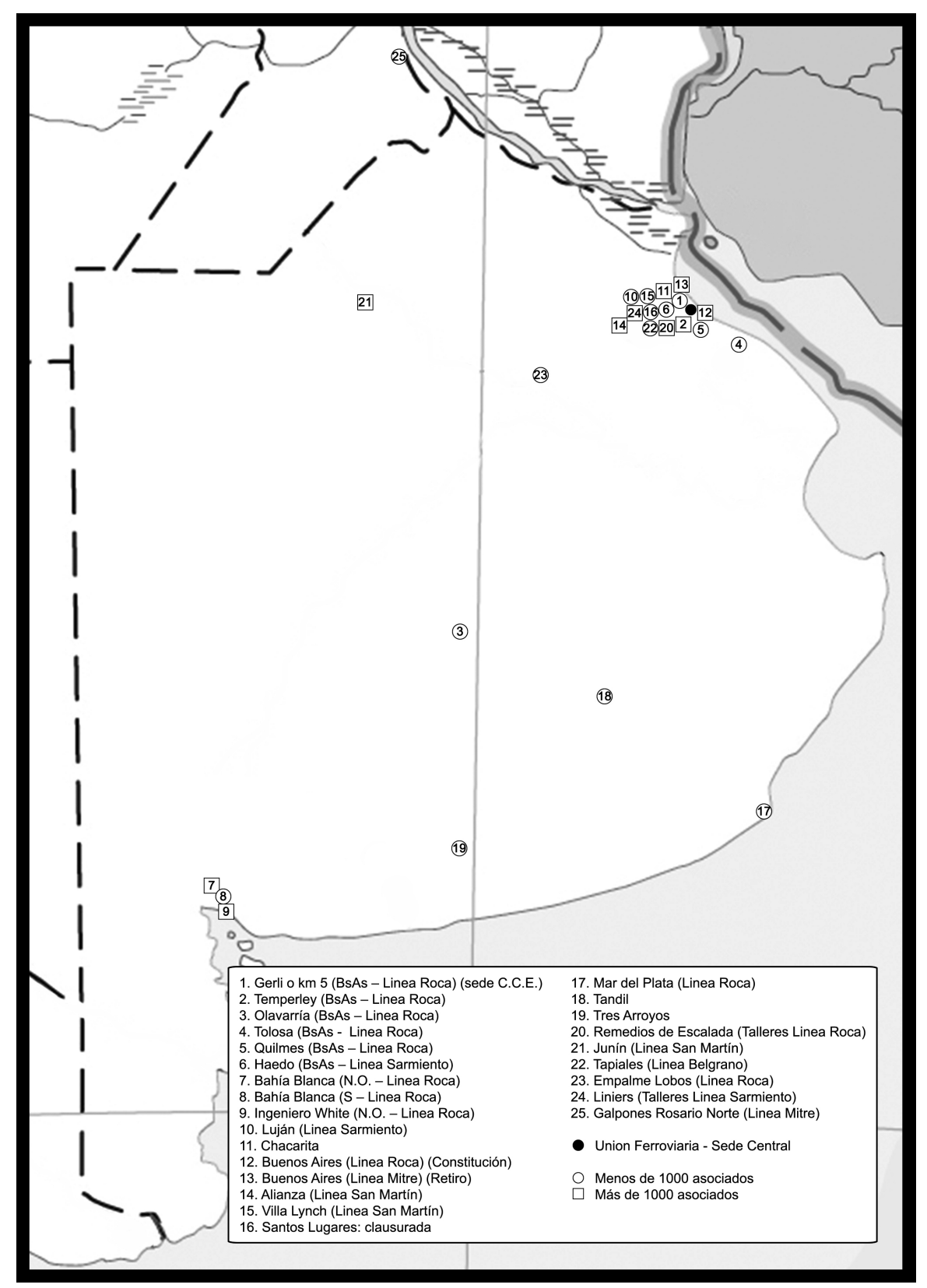

Fuente: Elaboración propia en base a datos registrados en los periódicos el Obrero Ferroviario, La Nación y La Prensa (durante el periodo de la huelga); y en trabajos historiográficos realizados sobre la huelga. ${ }^{32}$

El discurso de la C.D. de la U.F. -y del presidente J. D. Perón- intenta desactivar el conflicto recurriendo a dos estrategias. Una, definitoria del discurso institucionalista, a través de la satisfacción de las demandas particulares. La otra, definitoria del discurso populista, descalificando el movimiento en cuanto enemigo del pueblo y del justicialismo, es decir, estableciendo una frontera antagónica. ${ }^{33}$ En este último sentido, la interpelación a los trabajadores en cuanto peronistas se complementa con la categorización de los promotores de la huelga como ex miembros de la Unión Democrática.

${ }_{32}$ MENGASCINI, Hugo "Conflictos y Huelgas...", cit.; MARCILESE, José "El sindicalismo ferroviario...", cit.; y BADALONI, Laura "Control, memoria y olvido...", cit.

${ }^{33}$ LACLAU, Ernesto La razón populista, Fondo de Cultura Económica, Buenos Aires, 2005, p. 107. 
El 27 de noviembre, días después de finalizada la primer huelga, en el acto aniversario de la creación de la S.T.P., el presidente J.D. Perón remarca categóricamente "que la CD de la U.F. es de las más fieles peronistas que en este momento existe". ${ }^{34}$ A continuación sostiene que el sindicalismo argentino es "definitivamente libre y hace lo que se le antoja dentro de su organización". ${ }^{35}$ Por su parte, la C.D. de la U.F. y la cúpula de la C.G.T., buscan afirmar su posición como únicos representantes de los trabajadores. Dos días después de la reunión con el presidente, la C.G.T. hace una cena de camaradería en apoyo a la U.F. Allí, los dirigentes del gremio del riel señalan:

"que los agentes de la ex Unión Democrática que generaron estos hechos, no se dan por vencidos, pues ya se les ve desplazarse por las seccionales (...) en un desesperado esfuerzo por conseguir que las mismas adopten pronunciamientos adversos al cuerpo directivo". El gremio advierte a "los trabajadores peronistas" que "deberán permanecer alerta y contrarrestar con toda energía la acción destructiva de aquellos." 36

Sin embargo, muy a pesar de la posición institucional, la identificación con el peronismo es un elemento en disputa en el conflicto. Desde el primer momento, la identificación de la C.C.E. con la obra del gobierno es explícita. Evitaremos el debate sobre las motivaciones ocultas tras este discurso, que eternizan la polémica de sí el discurso de los huelguistas corresponde a un sentimiento "genuino" o, por el contrario, se trata de un "entrísmo", como estrategia de dirigentes que en realidad son opositores. El objeto de análisis que aquí se pondera es el efecto de ese discurso, afirmado en la identificación con el peronismo. El éxito de la huelga depende de generar legitimidad popular en el gremio del riel, y esa legitimidad -por lo menos así lo expresan los huelguistasla otorga la inscripción significante en la superficie discursiva peronista: "los componentes de esa comisión se hallan identificados con la obra y la política del gobierno nacional y como trabajadores ferroviarios apoyan con todas sus fuerzas la obra de justicia social y colaboran con la exitosa administración de los ferrocarriles nacionales." ${ }^{37}$ En este sentido, la condición hegemónica del peronismo presupone la eficacia simbólica del peronismo como sinónimo del pueblo trabajador. En este contexto político particular, la identificación peronista es condición de posibilidad de la articulación equivalencial de demandas.

Luego del primer conflicto, la C.C.E. se fortalece. Una magra respuesta salarial y una escalada de intervenciones sobre las seccionales más importantes (de las involucradas en el conflicto), permite a los dirigentes que conducen la huelga sumar nuevas voluntades contra la dirección del gremio. El 1 de diciembre se interviene la seccional $\mathrm{Km} \mathrm{V}$ de Gerli (que funciona como sede de la C.C.E.). El 3 de diciembre se interviene el local de Quilmes y el 7, la seccional de Bahía Blanca (N.O.). En Ing. White y Lujan rechazan la Circular General que envío la C.D. y se pliegan a la C.C.E. El 8 se interviene la seccional Olavarría. El 12 , un grupo se retira de la seccional chacharita adhiriendo a la posición de los huelguistas y solicitando la expulsión de la C.D. El 13 seccional. El 13 la seccional Haedo se pliega al apoyo a la C.C.E. ${ }^{38}$

\footnotetext{
${ }^{34}$ El Obrero Ferroviario, 597:T.

${ }^{35}$ La Nación, 28 de noviembre, p. 4.

${ }^{36}$ El Obrero Ferroviario, 597:4.

${ }^{37}$ La Prensa, 15 de diciembre, p. 5.
} 
Pero, a la condición subjetiva de reconocer su identificación con el peronismo, se suman otras condiciones objetivas de igual importancia para la eficacia de la medida de fuerza. La paralización total de una de las líneas más importantes del país, sumado a la paralización parcial en otras líneas importantes, sumaba volumen al capital organizativo de esta dirigencia ad hoc. Además, contaban con capital de negociación. Los años de doble afiliación y competencia entre la U.F. y la C.P.C.N., otorgaban a muchos dirigentes del nuevo movimiento ventajas organizativas y contactos en las gerencias de las empresas (sobre todo en el Roca) y en el Ministerio de Transportes. Estos elementos son fundamentales para comprender la fortaleza del movimiento huelguístico.

El 11 de diciembre, el C.C.E. emite un comunicado advirtiendo que se desconoció lo que, "altos funcionarios", les prometieron. El funcionario era el Cnel. José Roberto Zubieta, quién había sido gerente del F.C.N.G.R. y presidente del Directorio de los Ferrocarriles del Estado (del que Pablo C. López era vice). Luego del primer conflicto, el 6 de diciembre (¿cómo premio a la labor realizada durante el conflicto?) asciende a subsecretario técnico del Ministerio de Transportes, reemplazando a Ángel A. Ricotti. ${ }^{39}$ La C.C.E., fortalecida en su poder de negociación, aumenta la apuesta y "hace público su deseo de entrevistarse con el primer magistrado".

En la declaración de la segunda huelga, que inicia el 14 de diciembre a las 00hs, la demanda ferroviaria era categórica, la dirigencia del gremio debía renunciar porque perjudicaba al gremio y al peronismo: "se ha convertido en un elemento perturbador de la exitosa administración de los ferrocarriles nacionalizados por el general Perón y regidos por el ministro de transportes de la Nación, dificultando así el esfuerzo cotidiano del gremio en este sentido" ${ }^{40}$

La misma noche en que la C.C.E. anuncia la nueva medida de fuerza (13 de diciembre), la U.F. solicita que se concurra a asambleas urgentes en las cabeceras de los distintos ferrocarriles para escuchar al Ministro de Transporte. Con esta gira del ministro J. F. Castro en pleno conflicto, la dirigencia del gremio parecía entregar el estrado y el poder. Además de un reconocimiento de la pérdida de legitimidad, el gremio había perdido su autoridad institucional. Tanto los que apoyan como los opositores a la dirigencia ferroviaria, saltan a la dirigencia y envían telegramas a la presidencia y al ministerio de transportes, ya se afirmando su apoyo o solicitando la renuncia de la C.D. ${ }^{41} \mathrm{El}$ poder del sindicato del riel desnudaba su esencial vacuidad, la U.F. estaba, por primera vez en su historia, acéfala.

Para el gobierno era imperioso llenar ese vacío. El espectro del pueblo asomaba su silueta, amenazando el fundamento del orden institucional. ${ }^{42}$ Sin embargo, a diferencia de hace unos años, ahora, el orden era el orden peronista.

\footnotetext{
38 Las actividades de estas seccionales se encuentran en los periódicos de La Prensa de diciembre de 1950, en los días posteriores a las fechas consignadas.

${ }^{39}$ La Prensa, 6 de diciembre de 1950, p. 7.

${ }^{40}$ La Prensa, 14 de diciembre de 1950, p. 4.

${ }^{41}$ Entre el 15 y 17 de diciembre, durante los días más intensos del conflicto, se envían telegramas al ministerio de transporte y al presidente apoyando a la C.D. del gremio desde seccionales importantes, como Córdoba y Santa Fe (La prensa, 15 y 16 de diciembre de 1950, pp. 5 y 6.). El Dto. de tráfico de Junín, envía telegrama a J.D. Perón y J.F. Castro solicitando la renuncia de la C.D. (La Prensa, 17 de diciembre de 1950, p. 3).

${ }^{42}$ Respecto a la espectralidad del pueblo como amenaza a toda forma de institucionalidad en el populismo, ver BARROS, Sebastián Espectralidad e inestabilidad institucional. Acerca de la ruptura populista, VII Congreso Nacional de Ciencia Política, Saap, Córdoba, 2005.
} 
El presidente Juan D. Perón, es consecuente durante todo el conflicto en lo que a la defensa de las jerarquías institucionales se refiere. El 27 de noviembre había dicho que: "se equivocan si creen que el gobierno va a ir a intervenir un sindicato (...) el sindicato es para mí y para el gobierno una institución respetable que solo puede ser intervenida por sus autoridades, no por el gobierno". ${ }^{43}$

Casi dos meses después, el día en se decreta la movilización del personal ferroviario, poniendo un drástico final al conflicto, vuelve a insistir sobre la jerarquía institucional y la necesidad de conservarla: "si nosotros aceptáramos que es posible negociar asuntos gremiales con comisiones de emergencia, las comisiones directivas de los gremios estarían de más (...) y todas las autoridades gremiales caerían automáticamente al suelo."

Lo paradojal de la situación es que, si en el aspecto político el gobierno parecía ser el único "pescador" en un "río revuelto"; en el orden institucional continuando con la metáfora- la fuerza de la corriente amenazaba con socavar los cimientos de la ribera, arrastrando al pescador y su caña. La frontera antagónica -que aquel 17 de octubre dividió claramente al peronismo del antiperonismo, al pueblo de sus enemigos- se deslazaba hacia el campo peronista y abría una brecha, por la que cualquiera podía entrar o salir. Los dirigentes huelguistas sabían que perder la legitimidad peronista, era perder. Por eso, el 15 diciembre, la C.C.E. emitía un comunicado aclarando que "se trata de un problema estrictamente gremial" y que: "los componentes de esa comisión se hallan identificados con la obra y la política del gobierno nacional y como trabajadores ferroviarios apoyan con todas sus fuerzas la obra de justicia social y colaboran con la exitosa administración de los ferrocarriles nacionales" ${ }^{44}$

El conflicto había tomado dimensiones irreversibles. La huelga crecía en cantidad de adherentes e intensidad. Se sumaban algunos talleres muy importantes, como el de Remedios de Escalada. ${ }^{45}$ En chacharita, el presidente de la seccional, Sábato Spósito, también decide declarar su apoyo a la huelga y a la C.C.E. ${ }^{46}$ En Mar del Plata, el tren sale pero conduce personal administrativo. Mientras tanto, en la terminal, un grupo de "obreros ferroviarios de Mar del Plata" apoyan la huelga. Cuando el tren pasa por Lujan, es apedreado y se produce un sabotaje con el corte de las líneas de teléfono. ${ }^{47}$ El 16 de diciembre Tandil se pliega a la segunda huelga y también se forma una comisión paralela. Se cierran los locales de Villa Lynch y Santos Lugares, ${ }^{48}$ y es cesanteado el presidente seccional de Tres Arroyos. ${ }^{49}$ Por su parte, el gremio de maquinistas aclara que no adhiere a la huelga, pero que solo saldrán los trenes que tengan garantías de seguridad. Esas garantías no existen, según las seccionales de L.F., en Capital Federal, en puntos clave del conurbano bonaerense (como Haedo o Remedios de Escalada) ni en Rosario. ${ }^{50}$ El apoyo solapado de algunas seccionales de La Fraternidad a la huelga, es más que una sospecha. En Junín, detienen a dos dirigentes maquinistas en medio de una asamblea. ${ }^{51}$

\footnotetext{
${ }^{43}$ El Obrero Ferroviario, 597:T.

${ }^{44}$ La Prensa, 15 de diciembre de 1950, p. 5.

${ }^{45}$ La Prensa, 16 de diciembre de 1950, p. 6.

${ }^{46}$ La Prensa, 17 de diciembre de 1950, p. 3.

${ }^{47}$ La Prensa, 16 de diciembre de 1950, p. 6.

${ }^{48}$ La Prensa, 15 de diciembre de 1950, p. 5.

${ }^{49}$ MENGASCINI, Hugo “Conflictos y Huelgas...", cit., pp. 12-13.

${ }^{50}$ La Prensa, 17 de diciembre de 1950, p. 3.

${ }^{51}$ La Prensa, 16 de diciembre de 1950, p. 5.
} 
El 16 de diciembre a la tarde, con el conflicto in crescendo, la C.D. presenta la renuncia por segunda vez en un mes. A diferencia de la primera, esta tiene carácter "indeclinable". El Ministerio de Transporte se afirma como autoridad en el conflicto y resuelve la primera medida disciplinaria contra los huelguistas. Exonerar a todo trabajador ferroviario que no concurra a su trabajo al día siguiente. ${ }^{52}$ Con la C.D. fuera de juego, la C.C.E. apostaba por un paso más, y pedía se respete su legitimidad como representantes de los intereses del gremio. El "dedo en la llaga" de la jerarquía institucional, nuevamente. Para el gobierno, en un momento de particular vocación disciplinaria hacia el sindicalismo, esa atribución se tornaba inaceptable.

Con el sindicato acéfalo, pero aún con la medida de fuerza vigente, al otro día se reúnen miembros del C.C.E. con los "altos funcionarios". Técnicamente, todos los ferroviarios que no concurrieron al trabajo ese día, incluidos los miembros del C.C.E., habían sido cesanteados. Luego de la reunión, el 17 a la tarde, el presidente de la seccional Buenos Aires del F.C.N.G.R., Antonio Santos, toma posesión nuevamente del local seccional ubicado en el barrio de Barracas (Capital Federal). Allí, con numerosa presencia de trabajadores del riel y en un clima de victoria le hablaba "al gremio", no sin antes cantar el himno nacional. ${ }^{53}$ Minutos después, toma la palabra la máxima autoridad del evento, Lorenzo Martorelli (Tolosa), presidente del C.C.E. La apertura del discurso es contundente: "nuevamente estamos viviendo una era revolucionaria dentro de una revolución y esa revolución es pura y exclusivamente gremial". ${ }^{54}$

Al cierre de la asamblea se explica el convenio acordado con el Ministerio de Transportes. Se destaca un punto que cada vez cobra más protagonismo: libertad sindical para darse autoridades. ${ }^{55}$ La actividad ferroviaria, una semana antes de navidad, volvía a la normalidad.

\section{El traspaso del poder en la U.F.}

El traspaso del poder en la U.F. continuaba pendiente, y la posición de los huelguistas estaba clara, solo ellos decidirían la conducción. Sin embargo, se encontraba en vigencia el llamado a una asamblea extraordinaria para el día 21 de diciembre, originalmente convocada por la C.D. para tratar el asunto de la huelga. Ahora, esa asamblea se imponía como el día para definir la conducción del sindicato. Los de uno y otro lado del conflicto prometían hacerlo "sobre rieles" peronistas. La carrera por ocupar la silla del sindicato había largado. En la U.F., la C.D. entregaba su renuncia a la Junta Consultiva. La derrota de Pablo C. López lo puso en pie de guerra. Lejos de ser un soldado derrotado, era uno de los dirigentes más cercanos y leales a Perón y su esposa. ${ }^{56}$ En medio de la reunión que rubricaba el destino de la C.D., desenmascara la existencia de un

\footnotetext{
${ }^{52}$ La Prensa, 16 de diciembre de 1950, p. 5.

${ }^{53}$ La versión de la U.F. sobre esta asamblea es que "la CD declara terminantemente que la misma carece de validez estatutaria" (El Obrero Ferroviario, 597:6). Formalmente, la C.D. había renunciado el día anterior.

${ }^{54}$ La Prensa, 18 de diciembre de 1950, p. 5.

${ }^{55}$ Los puntos completos son: bonificación de $\$ 100$ a $\$ 180$, retroactivo al 1 de diciembre; aumento de los sueldos bajos, en relación a peones y guardabarreras a partir de un nuevo escalafón; levantamiento de medidas disciplinarias; libertad de los detenidos; libertad sindical para darse autoridades y pago de los días de paro. La prensa, 18 de diciembre de 1950, pp. 4-5.

${ }^{56}$ Aún era miembro del C.C.C. de la C.G.T. y vicedirector del directorio de los ferrocarriles del estado.
} 
enemigo interno: "altos funcionarios del ministerio de transporte se negaron con anterioridad a conceder las mejoras (...) con el objetivo de estropear la marcha de la organización gremial" ${ }^{57}$

La Junta Consultiva, mostrando que el ex presidente aún tenía los resortes del mando, emite un comunicado a tono con las declaraciones de aquel: "altos funcionarios del ministerio de transportes de la Nación, con la abierta colaboración de la mayor parte de las superioridades ferroviarias, han fomentado el abandono de los servicios con la finalidad principal de destruir a la Unión Ferroviaria". ${ }^{58}$ La C.G.T., ese mismo día, se organiza para apurar la intervención de la U.F. Paradójicamente, la primera intervención sindical de la C.G.T. (o la primera que era legal según el estatuto), se hacía en detrimento de una dirigencia que había sido clave para aprobar dicha reforma en la central.

Como consecuencia de las denuncias de los dirigentes de la U.F., ese mismo día el Ministro de Transporte ofrece su renuncia al presidente de la Nación. Si bien el objetivo inmediato estaba cumplido -los trenes corrían nuevamente por las vías de todo el país- los medios utilizados por el ministerio para lograrlo habían quebrado la jerarquía institucional y, para empeorar el panorama, ahora este detalle era público. El "primer trabajador" recibe y guarda celosamente la carta de renuncia, mientras espera el desenlace final del conflicto.

Esa misma noche, la C.C.E. toma conocimiento de la inminente intervención de la C.G.T. en la U.F. y se pone en pie de guerra. Declara que el congreso extraordinario es un "acto ilegal" y que la Junta Consultiva es tan ilegítima como lo era la C.D.: "únicamente el gremio será quién reciba la renuncia de la comisión directiva". Agrega que, en el acto de mañana, van a tomar el control del sindicato y "se resolverá pacíficamente y sin interferencias extrañas de ninguna índole el problema de su organización". Las columnas de ferroviarios se organizan para marchar hacía la sede central. En la seccional de Haedo, bastión de la C.C.E. en el F.C.N.G.S., se resuelve "impedir que la C.G.T. intervenga" el sindicato. En la seccional Buenos Aires del F.C.N.G.R., se designan los comisarios para la columna de ferroviarios que se disponen a tomar posesión del sindicato. ${ }^{59}$

Un día antes de la asamblea extraordinaria la C.G.T. interviene el sindicato de la U.F. La resolución, que pone en práctica el flamante y polémico artículo 67 del nuevo estatuto de la central, fundamenta que:

"la escisión producida dentro de las filas del gremio ferroviario a raíz del conflicto, puede ahondarse y agravarse por imperio de la pasión que una de las partes pone en defensa de sus puntos de vista. Que tal estado de cosas puede ser aprovechado por los eternos enemigos de la revolución justicialista y de la causa de los trabajadores para ponerlo al servicio de sus intereses personales o políticos"

Dejando en claro de qué lado de la contienda se ubicaba, la intervención decide: "como primera medida, confirmar en sus funciones a todos los miembros de

\footnotetext{
${ }^{57}$ La Prensa, 20 de diciembre de 1950, p. 6.

${ }^{58}$ La Prensa, 20 de diciembre de 1950, p. 6.

${ }^{59}$ La Prensa, 20 de diciembre de 1950, p. 6.
} 
las comisiones ejecutivas con su actual composición al igual que las comisiones de reclamos centrales y locales." 60

Esta confirmación de autoridades seccionales, implicaba ratificar las intervenciones hechas por la C.D. anterior, lo que incluía a las seccionales de L. Martorelli y A. Santos, respectivamente. Finalmente, llega el 21 de diciembre.

Los ferroviarios amanecen con una noticia que busca restarle apoyo al movimiento huelguístico. La segunda circular de la intervención, reproduce la resolución del Ministerio de Trabajo y Previsión donde establece el aumento general de sueldos para el gremio ferroviario ${ }^{61}$ Curiosamente, la resolución, además de estar firmada por el Ministro José María Freire, la refrendaban dos funcionarios de segunda línea de la cartera de transportes, J. R. Zubieta e Ismael Castro. Los protagonistas hasta el momento, el ministro J. F. Castro y el dirigente de la U.F. Luis T. Echave, titular de la dirección de trabajo en los transportes, quedaban fuera del asunto.

En las vías, el panorama es tenso y expectante. Desde la noche anterior, la policía se encuentra acuartelada a lo largo del recorrido de la línea principal del F.C.N.G.R., que va desde La Plata hasta la terminal de Plaza Constitución. En las primeras horas de la mañana, en Tolosa, cientos de socios toman la seccional desplazando al interventor, Julio Vargas. Con esta acción, Lorenzo Martorelli se aseguraba el control de su seccional antes de marchar hacia la sede central. Entrada la mañana, las columnas que llegan a las terminales de Retiro y Constitución chocan con nutridos controles policiales que dispersan la concentración. Según la crónica del diario La Prensa, los manifestantes: "portaban banderas argentinas y estandartes en los cuales se había colocado, de un lado los retratos del presidente de la nación y su esposa, y del otro leyendas alusivas al propósito del acto" ${ }^{62}$

Finalmente, una columna de cientos de ferroviarios que escaparon al control policial, muchos de la seccional Buenos Aires (F.C.N.G.R.), llegan a las inmediaciones de la sede de Av. Independencia. Sin embargo, ya sobre la tarde, estos también son dispersados por la policía antes de llegar al edifico. ${ }^{63} \mathrm{El}$ asedio al castillo de la U.F., había fracasado. Por la noche, la C.C.E. se reúne nuevamente en Gerli, el local que la vio nacer. Allí elaboran un comunicado que busca pasar el mal trago, afirmar su legitimidad y ostentar capital de negociación. Expresan:

"profunda satisfacción por la materialización de las aspiraciones económicas del gremio concretadas por el Ministerio de Transportes de la Nación con colaboración de la Trabajo y Previsión, con lo cual se ha cumplido la palabra empeñada por el coronel Juan R. Zubieta"

El comunicado continúa denunciando la represión sufrida en esa jornada, aunque no se nombran responsables, evitando cualquier confrontación con el gobierno. Sin embargo, se destaca que la medida represiva "constituyó una flagrante violación de la política gremial expresada por el general Perón". Hacia el final, exponen su capital organizativo desmintiendo "categóricamente" las

${ }^{60}$ El Obrero Ferroviario, 598-599:2.

${ }^{61}$ El Obrero Ferroviario, 598-599:3.

6222 de diciembre de 1950, p. 5.

${ }^{63}$ Según la versión de la intervención: "un grupo que, contando generosamente, ascendía a 300 personas el que fue disuelto solo en los instantes en que pretendió cometer actos de violencia" (El Obrero Ferroviario, 598-599:5) 
versiones de un nuevo paro, afirmando así el pleno control y coordinación sobre las acciones directas de los huelguistas. Por último, vuelven a la carga contra la intervención, sentenciando que esta "no puede ser aceptada por el gremio" ${ }^{64}$

Al otro día, la intervención de la U.F. devuelve el golpe, aclarando que el convenio está firmado por el Ministerio de Trabajo y Previsión, negando así la legitimidad y gravitación de la negociación entre el C.C.E. y los funcionarios de transporte mencionados. ${ }^{65}$ En cuanto a la acción de la dirigencia en el sindicato, comienza una etapa de notoria aceleración en el tratamiento y resolución de demandas. El 28 de diciembre envían otra circular confirmando en sus cargos a los miembros del C.C.C., a los empleados administrativos del sindicato, al secretario gerente y a los funcionarios en reparticiones estatales. ${ }^{66}$ En resumen, los mismos dirigentes depuestos de la U.F. a raíz del conflicto, continuaban en sus cargos en el C.C.C. de la C.G.T. En la U.F., permanecían el secretario gerente y los dirigentes asignados a la administración del sistema previsional ferroviario. La propuesta de la C.G.T. era clara, algo cambiaba para que nada cambie. Para los huelguistas, la intervención les contestaba con un fósforo y un bidón de nafta.

\section{1: La batalla final}

La tregua para que las fiestas sean en paz parece cumplirse, pero el conflicto se reanuda al año siguiente. La C.C.E. solicitaba reconocimiento, sino tendría que hacer valer su existencia por otros medios. El 5 de enero, Lorenzo Martorelli envía un telegrama a la intervención de la U.F. solicitando una reunión. Paralelamente, una delegación de la C.C.E. (F.C.N.G.S.) envía un telegrama al Ministerio de Transporte, pidiendo que se reconozca a la C.C.E. como única autoridad de negociación y denunciando la falta de libertad sindical en las seccionales. ${ }^{67}$ No hay respuesta a los telegramas.

Un actor que sorpresivamente se había mantenido neutral hasta aquí, el sindicato de maquinistas, comienza a jugar sus cartas. Si el encuadramiento de La Fraternidad (L.F.) con el Partido Socialista había alejado al sindicato de la C.G.T. (y del peronismo) entre 1945 y 1947, el año 1950 volvía a tensar la relación. La última reforma del estatuto de la C.G.T. iba, según la perspectiva de los dirigentes fraternales, contra todos los principios tradicionales del sindicalismo. Primero, porque adoptaba la doctrina justicialista -rompiendo el precepto de prescindencia política- $\mathrm{y}$, segundo, porque limitaba la libertad sindical al habilitar que la central pueda intervenir las filiales. Durante el conflicto, el gremio de maquinistas se mantuvo oficialmente al margen, sin embargo, la intervención de la C.G.T. a la U.F. lo empujó a una toma de posición pública. En este contexto, la dirigencia de L.F. aviva el fuego emitiendo un comunicado que advierte que el aumento salarial otorgado "no impedirá la consideración racional de las escalas de sueldos actuales de modo que permitan adaptarse al costo de la vida". Más adelante, reafirma su posición contraria al nuevo estatuto de la C.G.T., solicitando que la intervención de la U.F. “dure el

\footnotetext{
${ }^{64}$ La Prensa, 22 de diciembre de 1950, p. 6.

${ }^{65}$ El Obrero Ferroviario, 598-599:5.

${ }^{66}$ El Obrero Ferroviario, 598-599:3.

${ }^{67}$ La Prensa, 5 de enero de 1951, p. 6. Una semana antes, el C.C.E. había denunciado que continuaban intervenidos los locales que no eran "adictos" a la C.G.T. (La Prensa, 29 de diciembre de 1950, p. 6.)
} 
tiempo estrictamente necesario". ${ }^{68} \mathrm{El}$ accionar en tándem con la C.C.E. se evidencia cuando esta emite un comunicado el mismo día. En él, afirma su confianza en "los valores sindicales del peronismo" $\mathrm{y}$, deslegitimando la intervención de la C.G.T., solicita que sea el gobierno el que intervenga en el conflicto. ${ }^{69}$

La respuesta de la intervención no se hace esperar. En una circular general emitida el 10 de enero, se efectúa el llamado a elecciones para febrero. Se pone en claro que los exonerados no pueden participar de las mismas. Además, para legitimar la medida se convoca a una reunión con los 252 presidentes seccionales del sindicato, para establecer los pasos a seguir en la normalización del gremio.

Si el gobierno aún mantenía cierta distancia con el conflicto, el 15 de enero se posiciona definitivamente. Hace efectiva la renuncia del ministro J.F. Castro junto con su equipo, entre ellos Roberto Zubieta Leal. ${ }^{70}$ Días más tarde, el ferroviario Luis T. Echave es relevado de sus funciones en la dirección de trabajo en los transportes y se anuncia que las funciones de la misma pasan al Ministerio de Trabajo y Previsión. ${ }^{71}$ El presidente J. D. Perón fundamenta las renuncias y los cambios ministeriales en que:

“El Ministerio de Transportes, violando la ley de asociaciones profesionales que le imponía no tratar con una comisión de emergencia, lo hizo. Por eso el Ministerio de Transportes ha sido reemplazado (...) decían que el Ministerio de Transportes había una Dirección de Trabajo. Quiere decir que habían establecido un nuevo Ministerio de Trabajo." 72

Se cerraba una etapa de oscuros conflictos entre la cartera de transporte y el gremio del riel. El 17 enero, el Ministro del Interior Ángel Borlenghi presenta al nuevo Ministro de Transportes, el Ingeniero Juan E. Maggi, quien actuaba en la cartera de obras públicas hasta ese momento. ${ }^{73}$

En medio de los cambios ministeriales, entre los días 16 al 18 de enero, se realizan las deliberaciones de los presidentes de las seccionales de la U.F. Lo resuelto en la reunión se presenta al gremio en una circular. Allí se instruye a los presidentes a que presenten en sus seccionales un informe sobre el conflicto, "sin carácter deliberativo", para luego proceder a la elección de candidatos para la C.D. ${ }^{74}$

Con la noticia de las renuncias y la puesta en marcha de la normalización del sindicato, la posición de la C.C.E. corre riesgo de debilitarse. En una acción que resultó un grito en el desierto, envían un telegrama al nuevo ministro

\footnotetext{
${ }^{68}$ La Prensa, 9 de enero de 1951, p. 7.

${ }^{69} \mathrm{La}$ Prensa, 9 de enero de 1951, p. 7.

70 Renuncian, además, Ismael Castro (director de marina mercante), Roberto Iglesias y Antonio

P. Castro (dirección nacional de estudio y racionalización) La Prensa, 16 de enero de 1951, p. 6 y 17 de enero de 1951, p. 5.

${ }^{71}$ La Prensa, 23 de enero de 1951, p. 6.

72 El Obrero Ferroviario, 598-599:6-7.

${ }^{73}$ La Prensa, 17 de enero de 1951, p. 5. Además, se reemplazan los Gerentes Generales de tres ferrocarriles: F.C.N.G.R. (Tomás Crivelli), F.C.N.G.S. (Octavio S. Vivas, en vez de Francisco Mora) y F.C.N.G.B. (Miguel Revestido). La Prensa, 20 de enero de 1951, p. 5.

${ }^{74}$ El Obrero Ferroviario,598-599:10-11.Mientras tanto, en la seccional de Temperley denunciaban que "son meras palabras sin sentido la armonía y unidad que dicen buscar" (17 ene p. 5)
} 
solicitando una audiencia "urgente". ${ }^{75}$ La efervescencia se percibe en algunas seccionales, aunque casi exclusivamente en la línea Roca y alguna seccional del Sarmiento. ${ }^{76}$ El 19 de enero, la C.C.E. eleva el tono y emite un comunicado diciendo que las elecciones son una "nueva burla al gremio a través de un fraude electoral en marcha", y que con ello se persigue el objetivo de "restituirle a Taccone, Pautasso y otros elementos repudiados (...) reservando a Pablo $\mathrm{C}$. López la presidencia del directorio de los ferrocarriles". Al día siguiente, cumplido el protocolo de solicitar el reconocimiento formal al nuevo ministro, aseguran que "a pesar de que la Comisión Consultiva está reconocida oficialmente por el ministerio", nadie respondió. ${ }^{77}$

Agotado el efímero y protocolar tiempo diplomático, dos días más tarde comienza la última huelga. La C.C.E. solicita abiertamente la entrega del gremio y, en consecuencia, la participación en la modificación del escalafón. Luego de una jornada de numerosas complicaciones en el transporte ferroviario, hacia la tarde, ratifican el estado de huelga para el día siguiente y advierten que "no es aceptable" que el nuevo ministro "derive el problema a la C.G.T.". Solo con la entrega del sindicato se levanta la medida. El comunicado continúa reafirmando la "adhesión a la política social y económica del gobierno" y, por último, solicitando "la intervención directa del presidente de la nación [quién] podrá solucionar con justicia las aspiraciones de los ferroviarios" ${ }^{78} \mathrm{Al}$ tercer día de huelga, vuelven a insistir en la "esperanza en que la intervención del general Perón, a cuya política han adherido en todo momento los trabajadores, resuelva en forma satisfactoria el presente conflicto". ${ }^{79}$

La intervención busca desactivar rápidamente el conflicto. Al segundo día de huelga, renuncian a su candidatura nueve ex-miembros de la C.D. saliente. También renuncian los representantes de la U.F. en el directorio de los ferrocarriles, Pablo C. López y Antonio Taccone. ${ }^{80}$ La continuidad de la huelga dejaba al descubierto que estaba atada, exclusivamente, a la entrega de la conducción del sindicato a la C.C.E.

Finalmente, como pedían unos y otros, interviene el presidente Juan D. Perón. El 24 de enero llama al secretariado de la C.G.T., y a los principales dirigentes de sindicatos de la Capital Federal y el gran Buenos Aires alineados en ella, a una reunión en el Salón Blanco de la casa de gobierno. La estrategia consistía en evitar que el conflicto, eminentemente ferroviario, urbano y bonaerense se propague fuera de la jurisdicción del riel. En la reunión, la posición de Juan D. Perón es contundente:

"si yo cediese en esto, mañana no habría dirigentes en el país que no fueran manoseados. Los sindicatos tienen el derecho de

\footnotetext{
${ }^{75}$ La Prensa, 20 de enero de 1951, p. 5.

76 Algunas de las seccionales intervenidas retoman reclamos particulares en coordinación con los de la C.C.E. En la seccional Alianza, un grupo de ferroviarios envía un comunicado al flamante Min. Juan E. Maggi, solicitando la reincorporación de compañeros y "la renuncia de la comisión ejecutiva de la seccional Alianza". En Chacarita también piden la reincorporación de cuatro ferroviarios cesantes desde una huelga local en noviembre de 1947. Por último, el diario La Prensa informa que en los talleres de Liniers se reúne una Comisión Coordinadora del F.C.N.G.S. La Prensa, 19 de enero 1951, p. 6 y 20 de enero de 1951, p. 5.

${ }^{77}$ La Prensa, 19 de enero de 1951, p. 6 y 20 de enero de 1951, p. 5.

${ }^{78}$ La Prensa, 23 de enero de 1951, .p. 6.

${ }^{79}$ La Prensa, 24 de enero de 1951, p. 5.

80 La Prensa, 23 de enero de 1951, p. 6 y El Obrero Ferroviario, 598-599:7. El 8 de febrero renuncian formalmente Pablo C. López y Antonio Taccone al directorio de los ferrocarriles del Estado. El Obrero Ferroviario, 598-599:4.
} 
elegir sus propios representantes. El Estado, por la ley de asociaciones profesionales, está obligado a respetar, reconocer y tratar con esos dirigentes (...) pondré toda la fuerza del Estado, si es necesario, para hacer cumplir esa ley que, por otra parte, ha sido hecha por los propios dirigentes obreros (...) de manera que la ley de asociaciones profesionales que da jerarquía y autoridad a los dirigentes gremiales, yo la he de hacer respetar"

Respecto a la identificación de la C.C.E. con el peronismo, el presidente enuncia la expulsión de los huelguistas al campo antagónico: "Estos bandidos están actuando disfrazados de peronistas porque gritan ¡viva Perón!" ${ }^{81}$ Luego de la reunión, el presidente J. D. Perón decretaba la movilización del personal ferroviario. ${ }^{82}$ Una particular interpretación de la facultad del gobierno para garantizar la seguridad nacional, que abría el camino a la utilización de las fuerzas armadas para intervenir y juzgar, bajo justica militar, a los huelguistas. ${ }^{83}$ Con la enérgica medida presidencial, la huelga termina ese mismo día. La normalización institucional tenía un altísimo costo. Como saldo, miles de obreros ferroviarios presos y cesanteados, la renuncia de la dirigencia de la U.F. y del Ministro de Transportes Juan F. Castro y su equipo.

\section{Epílogo}

Finalmente, las elecciones en el gremio ferroviario se desarrollan a fines de junio de 1951, y la nueva C.D. asume el 2 de agosto de ese año. ${ }^{84} \mathrm{El}$ cuerpo directivo conserva varios nombres de la C.D. anterior, exceptuando a los 9 (sobre 16 integrantes) que habían renunciado explícitamente a su candidatura. El nuevo presidente de la U.F. es Carlos Ernesto Rosales, un dirigente del departamento de tráfico del F.C.N.G.B., el único ferrocarril que nunca detuvo su marcha durante los conflictivos meses de huelgas. La primera actividad oficial de la nueva dirigencia es junto con la C.G.T. en un acto en apoyo a la candidatura presidencial de J. D. Perón, donde el movimiento sindical propone la vicepresidencia de Eva Perón. El llamado "cabildo abierto del justicialismo". La hegemonía del peronismo se consolida.

Sin embargo, es necesario resaltar otra consecuencia directa de la huelga. La transformación de la relación entre el sindicato y los ferrocarriles nacionales en este marco de hegemonía política peronista. Poco quedaba de aquellas expectativas, manifiestas desde 1947, de participación sindical en la administración y dirección de la empresa Ferrocarriles Argentinos. Junto con P. C. López, cayó también la confianza del gobierno en la capacidad institucional del sindicato para manejar la tensión de constituirse, a la vez, en representante de los intereses de los trabajadores y de las empresas. ${ }^{85}$ Los fantasmas políticos de un

\footnotetext{
${ }^{81}$ El Obrero Ferroviario, 598-599:6-7.

${ }^{82}$ El texto completo del decreto se encuentra reproducido en El Obrero Ferroviario, 598-599:4.

${ }^{83}$ El episodio abre una larga tradición de militarización de los conflictos obrero, práctica que se extiende en otros gobiernos bajo el paraguas del denominado "Plan CONINTES". Al respecto ver DAMIN, Nicolás Plan Conintes y resistencia peronista. 1955-1963, Instituto Nacional Juan Domingo Perón, Buenos Aires, 2010.

${ }^{84}$ El Obrero Ferroviario, 603:5.

${ }^{85}$ Esta transformación en la relación tiene su reflejo en el diseño institucional de los ferrocarriles, a mediados del año 1952 se crea la Empresa Nacional de Transportes (Decreto Núm.4128/52) sin que se registre participación obrera en la misma. CARDOZO, Daniel "El rol de los sindicatos ferroviarios en la planificación ferroviaria peronista (1948-1952)", XXIV Jornadas de Historia Económica, Universidad Nacional de Rosario, 2014, p. 17.
} 
gremio "indisciplinado", que era capaz de parar los ferrocarriles a pesar de que eran "suyos"; se enfrentaban a los fantasmas sindicales que conjeturaban un ministerio que persiguió "destruir al sindicato", como había publicado la Junta Consultiva hacia el final de la huelga.

En este contexto, luego de los agitados meses de conflicto gremial, lejos de un aplastamiento de la voluntad sindical se producen transformaciones en las prácticas del mundo sindical ferroviario. Esta mutua desconfianza se torna un principio de acción, dónde los intereses contrapuestos entre las empresas y los trabajadores ferroviarios logran canalizarse a través de una abierta confrontación. Empresa y sindicato, gerencia y trabajadores, volvían a constituirse en categorías antagónicas para el discurso y la práctica sindical ferroviaria. Capital y trabajo, se reacomodaban como categorías antagónicas.

La nueva C.D., a diferencia de la anterior, era plenamente consciente de que adoptar la posición de la gerencia, identificarse con sus problemas e intereses -aunque se ampare en que es la posición del peronismo- era insuficiente para mantener la legitimidad en el gremio. La estrategia de la nueva dirigencia tenía muy en cuenta que una parte significativa de las bases había marcado otro modo de identificación con el peronismo. Es decir, la confortable posición de la identificación con el peronismo y la acumulación de capital político en las esferas gubernamentales -elementos en los que se apoyaba la dirigencia anterior- no eran lugares seguros por si mismos para dirigir el sindicato.

Entonces, si bien los problemas del sindicato eran similares, la experiencia del último tiempo había dejado en claro que la estrategia de la dirección del gremio debía ser otra. En este sentido, José Lebbonatto, sobreviviente de la gestión anterior, advierte que:
“Tenemos que tomar cartas en este caso, porque de lo contrario cuando menos pensemos se nos producirá un descontento incontenible dentro del gremio y la que pagará los platos rotos será la $\mathrm{CD}$, ya que no faltará quien diga que las mejoras estaban listas para salir y, al hacerse cargo el cuerpo directivo, todo quedó paralizado. (...) No faltarán los que propongan una nueva "comisión de emergencia" para hacernos pisar la cascara de banana, como se dice vulgarmente. Hay gente interesada en perjudicar al cuerpo directivo, y son precisamente los que no nos van a perdonar." 86

Había quedado claro, con la caída de Pablo C. López, que la legitimidad popular de los dirigentes no era un pergamino que la voz del líder podía blindar. La experiencia del peronismo tenía en su base material, sobre la que se apoyaba la nueva estima de si de los que antes permanecían excluidos, un fundamento inalterable. La dirigencia sindical, luego de un período de adaptación al caótico horizonte de prácticas sindicales que habilitaba el gobierno del general J.D. Perón, debía revisar y reflexionar, a fuerza de un duro revés que le asestó el propio gremio ferroviario a su concepción del "nuevo sindicalismo", sobre sus compromisos con las demandas de las bases.

Luego del período de intervención de la C.G.T. en que se agilizaron muchos asuntos a causa de las presiones de la huelga, la nueva dirigencia del sindicato ferroviario denuncia una sistemática falta de atención de las gerencias

${ }^{86}$ Actas Unión Ferroviaria, 1951 (2):15-17. 
a sus reclamos. Así lo expresa abiertamente el flamante presidente de la U.F. en una reunión de la Comisión Directiva:

"conversamos casi una hora y media, luego llegó un señor y nos dejó a nosotros para atenderlo, lo que demuestra que no tuvo interés en escucharnos. Asimismo, el señor gerente nos demostró que duda de la honestidad de la CD de la UF, cuando dijo que él oía varias campanas y que la de la UF era una más (...) Nosotros le explicamos una cantidad de cosas relacionadas con los problemas del ferrocarril en el aspecto gremial, pero nos encontramos frente a un hombre que no conoce la industria (...) Agregó el señor gerente que ciertas dificultades se producían porque el personal no tenía disciplina, y que la UF debía encarar ese respecto, instruyendo al gremio sobre el comportamiento a seguir en el trabajo (...) A juicio del que habla, en el trabajo es la superioridad la que debe establecer la disciplina que reclama, pero al parecer no la sabe imponer." ${ }^{87}$

También el flamante diputado nacional por Tucumán y vicepresidente $2^{\circ}$ de la U.F. Isaac D. Moya, ilustra la nueva postura de la C.D. denunciando abiertamente las arbitrariedades de la cartera de transporte:

"de un tiempo a esta parte ha aparecido una serie de resoluciones al margen de los convenios de las empresas con la UF, los cuales desnaturalizan el escalafón. Una resolución del Min. de Transporte modifica las escalas del personal de operadores de control (...) en el FFCC Belgrano se suplanta al personal administrativo con peones, y a éstos no se les abona la diferencia de sueldo porque el Ministerio de Transporte sacó una disposición modificatoria del artículo 28 del escalafón donde dice que al personal administrativo no se le pagará diferencia de sueldo" ${ }^{\prime \prime} .8$

Luego de conflictivos años, plagados de intentos por unificar los sentidos del peronismo, la lenta sedimentación de prácticas y sentidos iba delineando un peronismo ferroviario como un modo particular de identificación, que de ningún modo era reductible a intereses políticos o gubernamentales. La extraña posición de la C.C.E. en la huelga, desdoblada en un peronismo irreverente con el gobierno, mostraba un pliegue del discurso peronista que se enfrentaba a sí mismo.

El alcance de las consecuencias de este proceso es paradójico. El discurso peronista, a fuerza de desdoblarse, lograba gestionar la tensión para procesar las disidencias internas. El enemigo encubierto del justicialismo, el "falso peronista", se transformaba en una figura retórica legítima para dirimir internas. Como efecto, la nueva potencia del reclamo ferroviario se canaliza por este punto de fuga que admite enunciar un enemigo dentro del propio movimiento peronista, generando estabilidad en la beligerancia. El conflicto empresa-trabajadores, que para los ferroviarios había sido un elemento central en la construcción de la frontera antagónica que consolida la identificación con el peronismo desde 1944 al permitir articular al peronismo con la defensa del interés de los trabajadores ferroviarios ante las empresas extranjeras, retornaba.

\footnotetext{
${ }^{87}$ Ignacio Rosendo. Actas Unión Ferroviaria, 1951 (11):19-20.

${ }^{88}$ Actas Unión Ferroviaria, 1951 (2):14.
} 
Sin embargo, ahora, esta frontera se fijaba dentro de la superficie discursiva peronista.

En este sentido, Ignacio Rosendo, que durante los duros días de huelga fue un activo defensor de la dirigencia de la U.F. en "el Roca", unos meses después, lejos de un discurso institucional, enfrentaba abiertamente al empresariado ferroviario:

"Evidentemente, esos funcionarios, tanto los del Roca como los del Belgrano, están trabajando, podríamos decir, en contra (...) del justicialismo que preconiza el excelentísimo señor Presidente de la Nación (...) ya que los asociados nos han elegido para que los representemos, no vamos a permitir que se juegue porque sí con la Unión Ferroviaria, como sucedió el año anterior, y la defenderemos cueste lo que cueste y caiga quien caiga." 89

La resolución de la huelga, con la sentencia definitiva del presidente desconociendo a los "bandidos" que gritan “¡viva Perón!”, habilitaba esta posibilidad. Lejos de resolver el conflicto, este se afianza. La incorporación de un principio antagónico dentro del discurso peronista otorga estabilidad, en un sentido estructural -permanencia en el tiempo, perpetuación, reproductibilidad- a esta tensión. Esta reconfiguración discursiva, que a primera vista pareciera el principio del fin de la hegemonía, sin embargo otorga permanencia en el tiempo, reproductibilidad, al discurso hegemónico y a la conflictividad interna del mismo. Uno de los apotegmas políticos clásicos del peronismo, utilizado aún en nuestros días, ilustra la paradoja estructural de la hegemonía peronista que proponemos: "los peronistas somos como los gatos, cuando parece que nos estamos peleando es que nos estamos reproduciendo".

Mar del Plata, abril de 2018.

${ }^{89}$ Acta Unión Ferroviaria, 1951 (11):20. 